\title{
Factor Structure of Items from the Personality Adjective Check List in a Sample of Normal Adolescents
}

\author{
Josep M. Tous ${ }^{1}$, Núria Pont ${ }^{2}$, and Ruben Muiños ${ }^{1}$ \\ ${ }^{1}$ Universidad de Barcelona \\ ${ }^{2}$ Universitat Oberta de Catalunya
}

\begin{abstract}
We present the results of a principal-components analysis of the Personality Adjective Check List (PACL) at the item level, rather than at the scale level. The PACL was constructed by Strack (1987) to evaluate the personality scales proposed by Millon (1981). Data were obtained from a sample of normal adolescents. A scree test was applied to determine the number of factors to be extracted, and the retained factors were then rotated using a varimax procedure. Using the data from this second analysis, congruence coefficients were calculated by correlating the factor weights from the two analyses of men and women. Results reveal the existence in the whole sample of five unipolar personality factors, which we have called: Aggressive, Conscientious, Inhibited, Impulsive and Gregarious. These are not similar to those obtained from a sample of normal adults. Keywords: abnormal personality types, adolescents, personality adjective check list, principal components analysis at the items level, personality disorders
\end{abstract}

\begin{abstract}
Se presentan los resultados de un análisis de componentes principales del Personality Adjective Check List (PACL) al nivel de los ítems en vez del nivel de escala. El PACL fue construido por Strack (1987) para evaluar las escalas de personalidad propuestas por Millon (1981). Los datos se obtuvieron de una muestra de adolescentes normales. Se aplicó una prueba scree para determinar el número de factores a extraer, y los factores retenidos se rotaron con el procedimiento varimax. Empleando los datos de este segundo análisis, se calcularon los coeficientes de congruencia al correlacionar los pesos factoriales de los dos análisis de varones y mujeres. Los resultados revelan la existencia en toda la muestra de cinco factores unipolares de personalidad, que hemos denominado: Agresivo, Concienzudo, Inhibido, Impulsivo y Gregario. No se parecen a los factores obtenidos de una muestra de adultos normales.

Palabras clave: tipos de personalidad anormal, adolescentes, listado de adjetivos de personalidad, componentes principales, análisis al nivel de ítems, trastornos de personalidad
\end{abstract}

Correspondence concerning this article should be addressed to: Josep Maria Tous. Departament de Personalitat, Avaluació i Tractaments Psicològics, Facultad de Psicología, Universidad de Barcelona. Ps. Vall d'Hebron, 171, 08035 Barcelona (Spain).Telephone: (34) 93312 51 08. Fax: (34) 9340213 62. E-mail: jmtous@ub.edu 
The Personality Adjective Check List (PACL) was developed and validated by Strack (1987) as an instrument of measurement in adults, containing nine scales to cover the eight basic personality types, plus one scale representative of the three severe personality types established by Millon (1981). The nine scales correspond to: (a) Introversive/Asocial, (b) Inhibited/Avoidant, (c) Cooperative/Submissive, (d) Sociable/Gregarious and Histrionic, (e) Confident/Narcissistic, (f) Forceful/Aggressive, (g) Respectful/Obsessive-Compulsive, (h) Sensitive/Negativistic, and (i) an Experimental Scale, representative of Schizoid, Cycloid, and Paranoid. Factor analysis of the nine PACL scales shows three higher order dimensions, namely Neuroticism, Psychoticism, and Extraversion-Introversion (Strack, 1987; Pont, 1998). These are comparable to the PEN model (Eysenck \& Eysenck, 1985)

The content of the adjective list (PACL) can be found in Millon's $(1983,1987,1996)$ multiple descriptions of abnormal personality types (i.e., asocial, avoidant, submissive, gregarious, narcissistic, aggressive, conforming, and negativistic). As these contents are the same as those appearing in descriptions of personality disorders in adolescence (Millon, Green, \& Meagher, 1982), we applied the PACL to a sample of normal adolescents with the aim of obtaining a personality profile predictive of the type of personality disorder most likely to appear in adolescents when faced with a crisis.

Strack and Lorr (1990) studied the PACL by factorial treatment of data obtained at the item level. In this work, five unipolar personality dimensions were obtained, called Aggressive/Dominant, Neurotic, Conscientious, Detached/Introverted, and Surgent/Extraverted. We replicated Strack and Lorr's work in order to obtain a personality profile that would predict the most likely personality disorder in adolescents when facing a crisis. We chose principal components analysis with varimax rotation based on all the items from the PACL, as this allows comparison of the personality factors obtained by adults with those obtained by adolescents.

\section{Method}

\section{Participants}

The participants in the present study were 2,250 adolescents, of whom $47.46 \%$ were male $(n=1,068)$ and $52.54 \%$ were female $(n=1,182)$, and came from three different samples: The first sample was used by Pont (1998) in her doctoral thesis on the factor analysis of the PACL scales, working with 703 adolescents, of whom $55.04 \%$ were male $(n=387)$ and $44.95 \%$ were female $(n=316)$; the second sample was used by Muiños (2003) to obtain his Advanced Research License (DEA), in which the correlation between the PACL and NEO-PIR scales was studied using the responses of 815 adolescents, of whom $56 \%$ were female $(n=457)$ and $44 \%$ were male $(n=358)$; and finally, a third sample was especially gathered for this study, consisting of 732 adolescents, of whom $43.98 \%$ were male $(n=323)$ and $56.02 \%$ were female $(n=409)$. The age range for the whole sample was 12 to 18 years $(M=$ 16.7). Forty-five percent of the whole sample $(n=1,012)$ were studying at technical college, and 55\% $(n=1,238)$ were in the final years of secondary education and high school.

\section{Instruments}

The same list of 153 different adjectives (PACL) compiled by Strack (1987) was used, having been translated into Spanish and back-translated by a native English-speaker in Pont's doctoral thesis (1998). The adjectives chosen by Strack reflect the different personality types at their normal or most adaptive level, and are therefore perfectly suitable for use in normal population samples.

\section{Procedure}

The checklist was administered collectively, together with other verbal tests, and in situations which did not involve selection or examination of candidates. Administration was the same for all the samples, with participants having to choose the adjectives which they believed best described them. The checklist was completed in an average time of 12 minutes. The informed consent of the students, in addition to that of their teachers and parents, was solicited and duly obtained. Protocols of over 120 and under 10 adjectives chosen were rejected. For these reason $12 \%$ of males and $10 \%$ of females were excluded.

\section{Results}

\section{Preliminary Analysis by Principal Components}

For all the statistical analyses, SPSS (11.1) was used. First of all, we calculated three intercorrelational matrices of $153 \times 153$ items for each sample, two separate ones for males and females, and one for males and females together. Principal components analysis was applied to each correlation matrix, obtaining the following results: for males, 48 factors with a value greater than 1, accounting for $62.4 \%$ of the variance, for females, 49 factors with a value higher than 1, accounting for $69.1 \%$ of the variance, and for the whole sample, 44 factors with values higher than 1 , accounting for $58.21 \%$ of the variance. Table 1 shows the ten primary factors with the highest value by sex of each subject, and for the whole sample. 


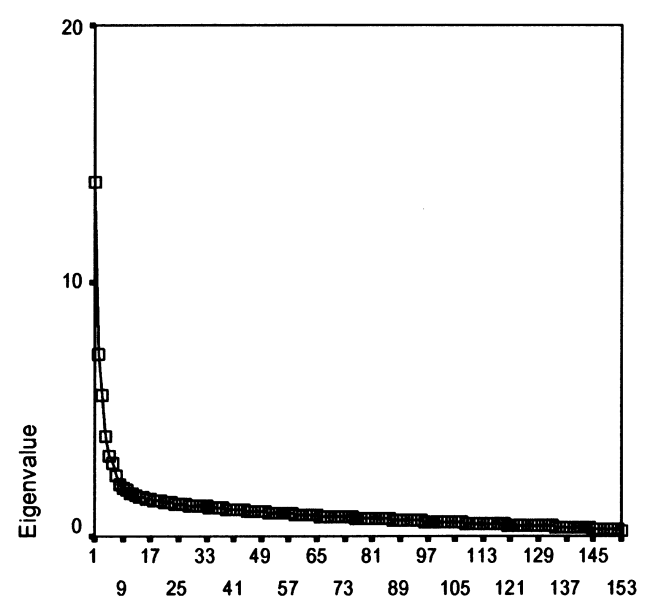

Number of components

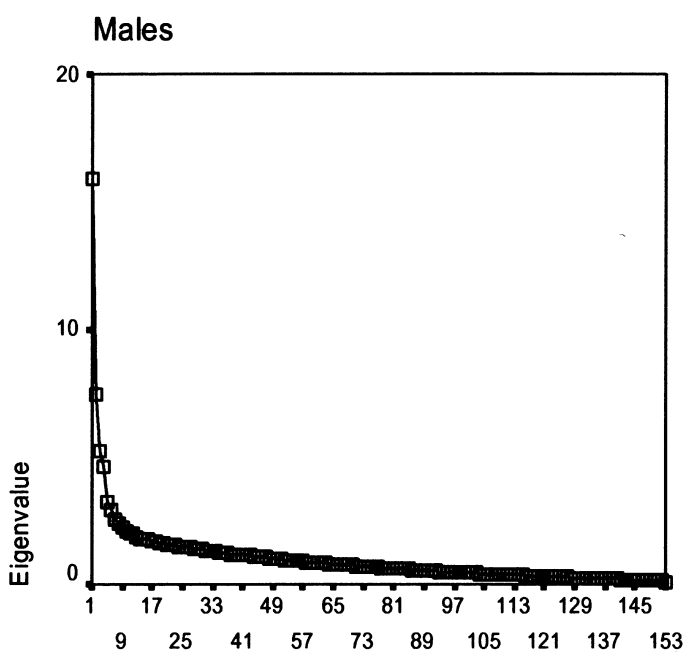

Number of components

Females

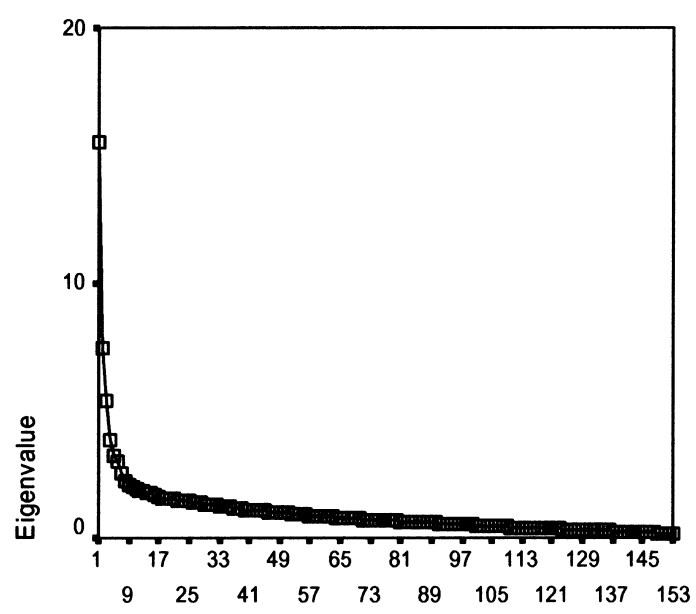

Number of components

Figure 1. Scree plot test to each sample of the principal components analysis.
Table 1

Eigenvalues Obtained with Principal Components Analysis for the First 10 Factors by Sex of Subject

\begin{tabular}{cccc}
\hline Factor & Men + Women & Men & Women \\
\hline 1 & 15.54 & 15.89 & 15.55 \\
2 & 7.23 & 7.50 & 7.43 \\
3 & 5.50 & 5.21 & 5.37 \\
4 & 3.88 & 4.58 & 3.84 \\
5 & 3.18 & 3.24 & 3.22 \\
6 & 2.87 & 2.92 & 2.98 \\
7 & 2.34 & 2.51 & 2.54 \\
8 & 2.04 & 2.42 & 2.22 \\
9 & 1.85 & 2.20 & 2.09 \\
10 & 1.82 & 2.07 & 2.02 \\
\hline
\end{tabular}

The scree plot proposed by Cattell $(1966,1978)$ was then applied to each of the principal components analyses (Figure 1) and allowed us to observe three similar slopes, identifying a maximum of five independent factors in each of the three analyses. From the factors obtained through the established standard criterion for the evaluation of factor structures obtained, we performed a principal components analysis, this time with varimax rotation, to obtain the most simple, unipolar solution for the factors (see Table 1). We used this kind of rotation because varimax produced the simplest overall solution for these analysis (Gorsuch, 1983), and it was also used by Strack and Lorr (1990).

Comparison of the factor solutions with varimax rotation for the three samples was made using congruence analysis, following the orthogonal procrustes rotation method used by Aluja, García, and García (2003), and the interpretation of congruence coefficients, in accordance with Chico, Tous, Lorenzo-Seva, and Vigil-Colet (2003). The following congruence coefficients were obtained: .92 between males and females for the whole list, .93 for the first factor, .96 for the second, .95 for the third, .91 for the fourth, and .86 for the fifth. These congruence coefficients reveal the satisfactory inter-factor comparability across the two samples studied. We therefore believe that our assumption of the existence of very similar factors in adolescent males and females cannot be rejected in this study.

\section{Principal Components Analysis with Varimax Rotation for the Whole Sample}

Table 2 shows the five factors obtained for the whole adolescent sample, using principal components analysis with varimax rotation. It must be remembered that only those adjectives saturating factors with loadings higher than .35 appear in the table, (the full table may be obtained from the first author), and that all the items load positively, meaning that all of the factors may be considered unipolar. The first factor (Aggressive) is made up of 23 adjectives which account 
for $10.5 \%$ of the variance. Most of them $(65.51 \%)$ come from two of the PACL scales, namely Forceful and Confident. The second factor (Conscientious) comprises 21 adjectives, which account for $4.7 \%$ of the variance, nearly all of them (87.49\%) from the Respectful and Cooperative Scales. The third factor (Inhibited) consists of 15 adjectives accounting for $3.6 \%$ of the variance, the great majority of which $(83.32 \%)$ come from the Inhibited and Sensitive Scales. The fourth factor (Impulsive), which is described by 17 adjectives with $2.5 \%$ of the variance accounted for, includes adjectives from different scales, in particular Sociable, Experimental, and Sensitive (68.4\%). The fifth and final factor (Gregarious) has ten adjectives, which account for $2.1 \%$ of the variance, and is made up almost entirely (90\%) of adjectives from the Sociable and Cooperative Scales.

Loadings of each scale for each factor are as follows: Factor 1: Forceful (37.93\%), Confident (27.58\%), Sensitive $(13.79 \%)$, Introversive $(6.89 \%)$, Inhibited $(6.89 \%)$, Sociable $(3.44 \%)$, and Cooperative (3.44\%); Factor 2: Respectful (54.16\%), Cooperative (33.33\%), Confident $(4.16 \%)$, Experimental (4.16\%), and Inhibited (4.16\%); Factor 3: Inhibited $(55.55 \%)$, Sensitive $(27.77 \%)$, Experimental $(11.11 \%)$, and Introversive $(5.55 \%)$; Factor 4 : Sociable (31.57\%), Experimental (21.05\%), Sensitive (15.78\%), Cooperative $(10.52 \%)$, Forceful $(10.52 \%)$, Respectful
(5.26\%), and Introversive (5.26\%); and Factor 5: Sociable $(60 \%)$, Cooperative $(30 \%)$, and Inhibited (10\%).

The borderline congruence (Chico et al., 2003) found in Factor 5 (Gregarious) between males and females (0.86\%) seems to be due primarily to the fact that the number of adjectives which load on this scale is 12 in the case of males, and 20 in that of females. Separate Factor 5 loadings for males and females are Sociable (50\%), Forceful (33.33\%), Confident $(8.33 \%)$, and Inhibited $(8.33 \%)$ in the case of the males, and Sociable (35\%), Cooperative (25\%), Forceful $(25 \%)$, Confident $(10 \%)$ and Inhibited $(5 \%)$ in the females.

\section{Discussion}

The results obtained in this adolescent sample coincide in four factors with those obtained by Strack and Lorr (1990) in their adult sample. Our first factor (Aggressive), saturated by items from the Forceful and Confident Scales, coincides fully with their first factor, which they called Aggressive/Dominant. Our second factor (Conscientious) coincides fully with their third factor, which they called Conscientiousness, given that both are saturated by items from the Respectful and Cooperative Scales. Our third factor (Inhibited) coincides with Strack and Lorr's second

Table 2

Items Loading .35 or above on Varimax-Rotated Factors for Men and Women Combined

\begin{tabular}{|c|c|c|c|c|c|c|c|c|c|}
\hline \multicolumn{2}{|c|}{ Factor 1} & \multicolumn{2}{|l|}{ Factor 2} & \multicolumn{2}{|c|}{ Factor 3} & \multicolumn{2}{|c|}{ Factor 4} & \multicolumn{2}{|l|}{ Factor 5} \\
\hline Item & Loading & Item & Loading & Item & Loading & Item & Loading & Item & Loading \\
\hline Aggressive & .502 & Neat & .613 & Depressed & .565 & Bubbly & .515 & Talkative & .564 \\
\hline Conceited & .502 & Orderly & .612 & Afraid & .551 & Aggravated & .512 & Playful & .503 \\
\hline Disagreeable & .483 & Hard-working & .577 & Fearful & .547 & Vivacious & .478 & Daring & .494 \\
\hline Blunt & .482 & Proper & .541 & Insecure & .543 & Lively & .469 & Animated & .489 \\
\hline Powerful & .480 & Formal & .538 & Confusing & .513 & Combative & .456 & Warm-hearted & .436 \\
\hline Tough & .478 & Obedient & .528 & Shy & .480 & Fearless & .435 & Merry & .411 \\
\hline Domineering & .471 & Organized & .523 & Oversensitive & .471 & Fluctuating & .434 & Uneasy & .410 \\
\hline Boastful & .439 & Industrious & .477 & Secretive & .454 & Virtuous & .427 & Adventurous & .409 \\
\hline Cool & .436 & Disciplined & .462 & Timid & .442 & Fickle & .426 & Agreeable & .400 \\
\hline Rigid & .434 & Careful & .452 & Pessimistic & .431 & Suspicious & .423 & Sweet & .357 \\
\hline Egoistic & .429 & Self-contented & .446 & Worried & .425 & Chaotic & .411 & & \\
\hline Revengeful & .426 & Respectful & .446 & Ill-at-ease & .409 & Outgoing & .409 & & \\
\hline Mean & .422 & Upright & .427 & Reserved & .404 & Helpful & .392 & & \\
\hline Self-important & .419 & Agreeable & .425 & Ignored & .366 & Erratic & .392 & & \\
\hline Rejected & .414 & Overlooked & .410 & Irritable & .353 & Yielding & .372 & & \\
\hline Arrogant & .402 & Gentle & .405 & Peppy & .365 & & & & \\
\hline Coy & .386 & Self-conscious & .404 & Disinterested & .354 & & & & \\
\hline Hesitant & .384 & Sweet-tempered & d .385 & & & & & & \\
\hline Impersonal & .375 & Decent & .382 & & & & & & \\
\hline Unafraid & .375 & Precise & .378 & & & & & & \\
\hline Militant & .371 & Fragmented & .363 & & & & & & \\
\hline Testy & .362 & & & & & & & & \\
\hline Vain & .358 & & & & & & & & \\
\hline
\end{tabular}


factor, as both are partly saturated by the Inhibition Scale and by items from the Sensitive Scale. In both cases, this factor could be labeled Neuroticism, given the meaning of the items which comprise it. The fourth factor in our study (Impulsive) bears no clear relationship to any of Strack and Lorr's factors, as despite consisting mainly of items from the Sociable, Experimental and Sensitive Scales, all of them are descriptive of impulsiveness. Our fifth factor is saturated almost exclusively by items from the Sociable and Cooperative Scales, and, to judge by the adjectives which form it, we believe it fully coincides with the fifth factor proposed by Strack and Lorr, namely Surgent/Extraverted.

The lack of optimal congruence in Factor 5 (Gregarious) between males and females can be explained quantitatively by the greater loading for females on this factor, and qualitatively by the fact that the Cooperative Scale was only present in females on this factor. From this comparison, we can only conclude that, unlike in Strack and Lorr's (1990) fourth factor (Detached/Introverted) in an adult sample, an introversion factor does not emerge in the adolescent sample. We believe that the likeliest explanation for the differences found is that an adolescent, rather than an adult sample was used. The PACL might, therefore, be a useful instrument in the prevention of personality disorders in adolescence.

The other investigation on the structure of normal and pathological personality dimensions was conducted by De Clerq and De Fruyt (2003) on nonclinical adolescents. They used the NEO-PI-R and found that facets could predict disorder symptoms. Given that we also find a five-factor structure, we consider our results can be placed within the five-factor model perspective, and the relations between our five factors and those from the NEO-PI-R should be studied in the future.

\section{References}

Aluja, A., García, O., \& García L.F. (2003). Replicability of the three, four and five Zuckerman's personality super-factors: Exploratory and confirmatory factor analysis of the EPQ-RS, ZKPQ and NEO-PI-R. Personality and Individual Differences, 36, 1093-1108.
Cattell, R.B. (1966). The scree for the number of factors. Multivariable Behavior Research, 1, 245-276.

Cattell, R.B. (1978). The scientific use of factor analysis in behavioral and life science. New York: Plenum Press.

Chico, E., Tous, J.M., Lorenzo-Seva, U., \& Vigil-Colet, A. (2003). Spanish adaptation of Dickman's impulsivity inventory: Its relationship to Eysenck's personality questionnaire. Personality and Individual Differences, 35, 1883-1892.

De Clerq, B., \& De Fruyt, F. (2003). Personality disorder symptoms in adolescents: A five factor model perspective. Journal of Personality Disorders, 17, 269-292.

Eysenck, H.J., \& Eysenck, M.W. (1985). Personality and individual differences. A natural science approach. New York: Plenum Press.

Gorsuch, R.L. (1983). Factor analysis. Hillsdale, NJ: Erlbaum.

Millon, T. (1981). Disorders of personality: DSM-III, Axis II. New York: Wiley.

Millon, T. (1983). Modern psychopathology. Prospect Height, IL: Wavelan Press.

Millon, T. (1987). Manual_for the Millon Clinical Multiaxial Inventory-II. Minneapolis, MN: National Computer Systems.

Millon, T. (1996). Disorders of personality. DSM-IV and beyond. New York: Wiley.

Millon, T., Green, C. J., \& Meagher, R.B. (1982). Millon Adolescent Personality Inventory manual. Minneapolis MN: National Computer Systems.

Muiños, R. (2003). Significación de los indicadores del PMK-RD a partir de diferentes pruebas verbales de personalidad. Unpublished Advanced License research (DEA). Facultad de Psicología. Universidad de Barcelona.

Pont, N. (1998) Adaptación y baremación de un listado de adjetivos para la evaluación de la personalidad adolescente. Unpublished doctoral dissertation. Facultad de Psicología. Universidad de Barcelona.

Strack, S. (1987). Manual for the Personality Adjective Check List (PACL). Draft Psychology Service, 116b. Veterans' Administration Outpatients Clinic.

Strack, S., \& Lorr, M. (1990). Item factor structure of the Personality Adjective Check List (PACL). Journal of Personality Assessment, 55, 86-94.

Received January 26, 2006

Review received May 25, 2006 Accepted May 31, 2006 


\section{Appendix}

\section{Items comprising the PACL Scales}

Scale 1, Introversive, $n=19$ : reserved, remote, yielding, sluggish, apathetic, unemotional, rigid, uninspired, solitary, subdued, expressionless, indifferent, detached, uncomfortable, serious, disinterested, impersonal, inexpressive, distant.

Scale 2, Inhibited, $n=27$ : ignored, insecure, oversensitive, apprehensive, timid, uneasy, afraid, yielding, worried, depressed, fearful, shy, excluded, solitary, touchy, moody, hesitant, nervous, unnoticed, lonely, anxious, apologetic, uncomfortable, overlooked, self-conscious, ill-at-ease, rejected.

Scale 3, Cooperative, $n=26$ : consenting, oversensitive, innocent, yielding, agreeable, naive, shy, traditional, decent, conforming, hesitant, proper, docile, obedient, apologetic, gentle, sweet, self-conscious, helpful, dependent, cooperative, trustful, respectful, sweet-tempered, warm-hearted, understanding.

Scale 4, Sociable, $n=21$ : playful, extravagant, bubbly, gregarious, vivacious, daring, peppy, lively, outgoing, fickle, animated, talkative, coy, dramatic, adventurous, care-free, sociable, seductive, theatrical, flirtatious, merry.

Scale 5, Confident, $n=22$ : self-satisfied, boastful, extravagant, intimidating, arrogant, selfish, cool, vivacious, daring, self-centered, overconfident, care-free, seductive, self-admiring, self-contented, egoistic, conceited, powerful, self-important, righteous, immodest, vain.

Scale 6, Forceful, $n=26$ : intimidating, courageous, competitive, arrogant, cool, daring, overconfident, fearless, militant, blunt, adventurous, commanding, combative, bossy, mean, disagreeable, powerful, self-important, domineering, revengeful, unafraid, forceful, tough, hard-headed, aggressive, hostile.

Scale 7, Respectful, $n=21$ : strict, careful, industrious, virtuous, upright, straight-laced, precise, disciplined, neat, traditional, conforming, proper, orderly, obedient, formal, efficient, moralistic, organized, serious, respectful, hard-working.

Scale 8, Sensitive, $n=26$ : insecure, apprehensive, edgy, erratic, aggravated, fluctuating, temperamental, testy, depressed, annoyed, irritable, baffling, touchy, moody, nagging, blunt, nervous, anxious, complaining, grouchy, bossy, confusing, mean, disagreeable, ill-at-ease, pessimistic.

Scale 9, Experimental, $n=11$ : erratic, chaotic, fragmented, worried, aggravated, depressed, secretive, nervous, despondent, suspicious, confusing. 